http://jmscr.igmpublication.org/home/ ISSN (e)-2347-176x ISSN (p) 2455-0450 crossref DOI: https://dx.doi.org/10.18535/jmscr/v8i7.06

\title{
Pediatric Primary Hypoparathyroidism: A Case Report
}

\author{
Authors \\ Kanika Chauhan ${ }^{1}$, Aashutosh Sharma ${ }^{2} *$ \\ *Corresponding Author \\ Dr Aashutosh Sharma \\ M.D Pediatrics, ZH Dharamshala (H.P), India
}

\section{Introduction}

Hypoparathyroidism in children is a rare endocrine disorder characterised by primarily neuropsychiatric signs and symptoms and is liable to misdiagnosis. The most common cause is iatrogenic. Patients are usually asymptomatic, few patients however have symptomatic hypocalcemia. Children may precipitate episodes of seizures and tetany during periods of stress such as a febrile illness and maybe mislabelled as having febrile seizures or epilepsy. Misdiagnosis rates of primary hyperparathyroidism are very high $(29 \%)^{1}$.

\section{Case Report}

We report a case of an 11 year female adolescent presented with history of tetany and abnormal body movements over the last one day along with undocumented fever and rash 4 days back. There was no past medical history for seizures, abnormal body movements, radiation or previous neck surgeries or any chronic illness. The patient had stable vitals at presentation however she had tetanic episodes and seizures during hospital stay and developed encephalopathy. Patient was showing trousseau's and chvostek signs of hypocalcemia (figure 1). Physical examination revealed average anthropometric measurements- lying on $50^{\text {th }}$ centile. There were no dysmorphic features. Systemic examination was normal. Initial investigations had a normal blood picture with severe hypocalcemia with calcium level of 4.7 $\mathrm{mg} / \mathrm{dl}$ and hyperphosphatemia $8.2 \mathrm{mg} / \mathrm{dl}$ and raised ALP 222 IU and normal magnesium levels. Renal functions were preserved. $Q_{0}$ tc interval was prolonged on ECG. Vitamin d levels were normal. PTH levels were low (Table 1). Eye examination showed a hyperemic disc. Abdominal USG revealed no calcification sites. NCCT and MRI brain showed bilateral basal ganglia calcifications. Bilateral basal ganglia show calcification in the form of T2 hyperintensity. Calcifications were also seen in right caudate nucleus and bilateral frontal lobes and subcortical white matter. Other associations with thyroid, adrenals and ovaries were ruled out.

The child was started on iv calcium $1 \mathrm{~g}$ per $\mathrm{kg}$ per day along with calcitriol $2 \mathrm{mg}$ per day. There was gradual improvement in calcium levels and patient's general condition. The patient was discharged at a calcium level of $6.9 \mathrm{mg}$ per $\mathrm{dl}$. Gradually calcium supplementation was done orally. 


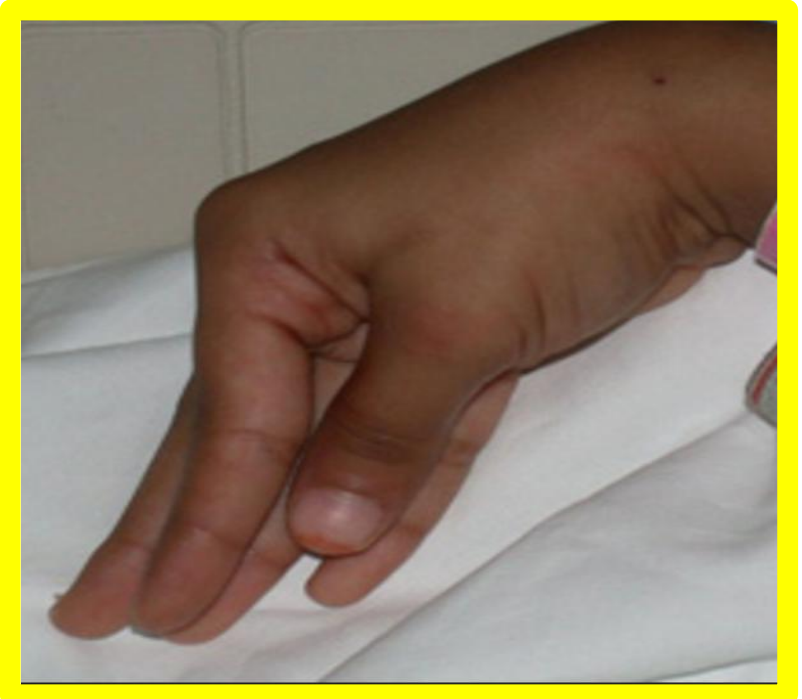

Figure 1: Trousseau's sign in the patient due to hypocalcemia.

Table 1: Effect of calcium supplementation on blood biochemistry of the patient

\begin{tabular}{|l|c|c|}
\hline Investigation & Before treatment & After treatment \\
\hline S calcium & $4 \mathrm{mg}$ per dl & $6.9 \mathrm{mg}$ per dl \\
\hline S phosphorus & $8.2 \mathrm{mg}$ per dl & $6.1 \mathrm{mg}$ per dl \\
\hline $\begin{array}{l}\text { Alkaline } \\
\text { phosphatase }\end{array}$ & $222 \mathrm{IU}$ & $155 \mathrm{IU}$ \\
\hline Vit D levels & $32 \mathrm{ng}$ per ml & - \\
\hline PTH levels & $8.8 \mathrm{pg}$ per ml & - \\
\hline
\end{tabular}

\section{Discussion}

Most common pathological cause of basal ganglia calcification is primary hypoparathyroidism: most common site being globus pallidus. Other areas affected by basal ganglia calcification include thalamus, dentate nuclei, cerebral cortex, grey white junction and the cerebellum. Our patient had basal ganglia calcification at rare sites: b/l frontal lobes and grey white junction. Treatment of symptomatic or profound asymptomatic hypocalcemia (Corrected Calcium (Ca) $<1.9 \mathrm{mmol} / \mathrm{L}$ ) is aimed at rapid intravenous administration of calcium and oral supplementation of vitamin D metabolites. Treatment goal is to keep a target serum calcium level in a low normal range i.e. 2 to 2.13 $\mathrm{mmol} / \mathrm{L}{ }^{2,3}$ In the long-term management: thiazide diuretics are of value as they enhance renal calcium reabsorption and increase serum calcium. It has been shown to lower urinary calcium losses. Careful monitoring of vitamin $\mathrm{D}$, phosphorous, and calcium is necessary during acute and longterm therapy. Use of PTH replacement therapy for hypoparathyroidism has shown benefit in recent studies, allowing reductions in the dose of calcitriol and calcium supplements, and is a promising therapeutic option. ${ }^{4}$

\section{Conclusion}

Serum calcium levels should be estimated in all patients with seizures, tetany, bilateral cataracts, dilated cardiomyopathy, movement disorders and basal ganglia calcifications. Hypocalcemia along with hyperphosphatemia and preserved renal function warrants PTH level estimation. Every patient of hypocalcemia should be investigated for cataract, hearing deficit and basal ganglia calcifications.

\section{References}

1. Zhang TL, Wang CM. Misdiagnosis of idiopathic hypoparathyroidism with dominant neuropsychiatric manifestations: analysis of 12 cases. J Shandong Med 2000;40:52-3.

2. Shoback D. Clinical practice: hypoparathyroidism. N Engl J Med 2008; 359:391-403.

3. Bilezikian JP, Khan A, Potts JT Jr. Hypoparathyroidism in the adult: epidemiology, diagnosis, pathophysiology, target-organ involvement, treatment and challenges for future research. J Bone Min Res 2011;26:2317-37.

4. Di Maio S, Soliman AT, De Sanctis V, Kattamis CC. Current treatment of hypoparathyroidism: Theory versus reality waiting guidelines for children and adolescents. Acta Biomed 2018 Mar 27;89(1):122-31. 